\title{
内蒙古白乃庙群变质基性火山岩 锆石铀一铅年龄*
}

\author{
最风军张沙涛
}

(中国地质科学院矿术地质研究阶, 北京 100037)

陈 琦 孟良义 他甘箖 李德纶

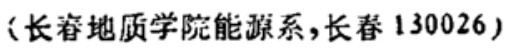

\section{关调铀一铅年龄、中元古代、内蒙古}

白乃庙群出露在内蒙古中南部地区(图 1), 研究区内以发育有温都尔庙蛇绿岩套, 混杂堆 积和白乃庙岛弧火山沉积岩系以及产出有一系列铁、铜、金矿床(点)而为人们所关注. 鉴于 白乃庙群及有关岩石地层的形成时代未能得到很好解决, 地质学家对于区内不同构造单元相 互关系、运动方式和原始空间位置一直存在不同认识, 从某种意义上讲影响了区内隐伏金属矿

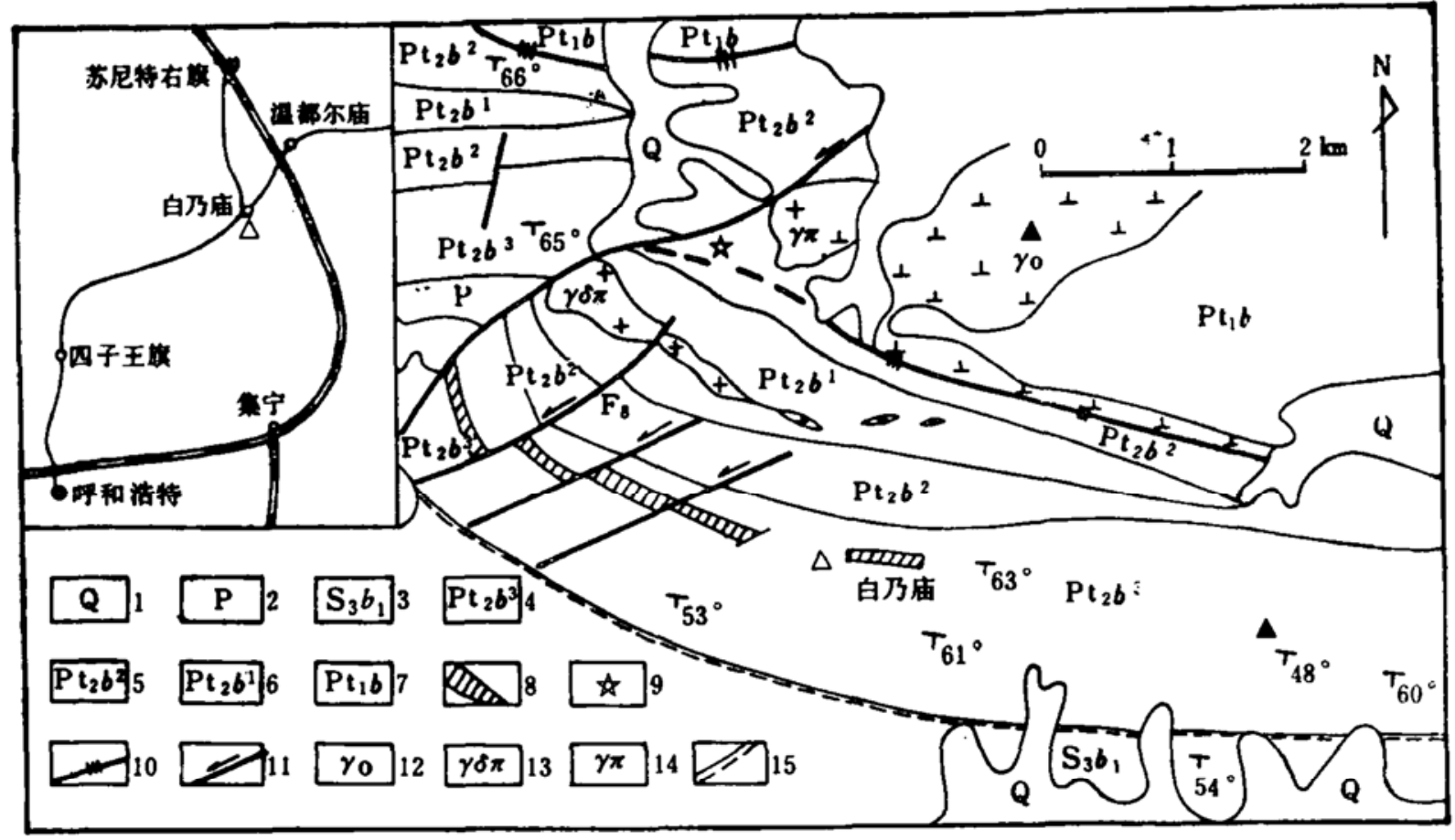

图 1 内蒙古白乃庙地区地质简图

1.第四系；2.二叠系沉积岩；3.志留系类复理石建造；4.白乃庙群上部岩性即；5.白乃庙群中部岩栍即：6.白 乃庙群下部岩性段； 7. 中元古代白银都西群变质岩系；8. 白乃庙铜矿；9. 白乃庙金矿；10.东西向断裂；11. 北 东向断裂；12. 石英闪长岩；13. 花岗内长玨岩；14.花岗㢺岩；15.不整合面

本文 1989 年 11 月 3 日收到.

“国家“七・五”重点地质科技攻关项目. 
床找矿勘探工作的进展. 白乃庙群同位素地质年代学研究开始于 70 年代中期,迄今所取得的 5 件钾-占 (全岩、黑云母和角闪石)同位素年代数据变化范围 $362-581 \mathrm{Ma}$, 一组全岩钩-镂同 位素等时年龄值为 $427.5 \mathrm{Ma}$, 部分地质学家据此将白乃庙群划属寒武-奥陶纪 ${ }^{[1]}$, 而另外一 些学者则基于区域岩石地层对比和地质构造研 究 资料, 将白乃庙群划归为中元古庙 ${ }^{D}$, 但缺少 同位素年龄数据方面的佐证. 作者在野外地质调查基础上, 选择白乃庙群上部岩性段基性火 山岩和邻近的石英闪长岩体为测定对象, 运用锆石铀一铅法对岩石的形成时代进行了研究.

\section{一、测试样品地质特征}

白乃庙群主要出在研究区内的白乃庙和谷那乌苏等地, 走向近东西, 为一套厚约 $2452 \mathrm{~m}$ 的浅-中变质绿片岩系, 其原岩为海相火山喷发-沉积建造. 白乃庙群底部与中元古宙 白银都西群 $(1700 \mathrm{Ma}, \mathrm{Sm}-\mathrm{Nd} \text { 法 })^{2}$ 变质岩系呈断层接触(图 1), 顶部为中晚志留纪类复理 石建造不整合覆盖. 一般认为白乃庙群自下而上大体可划分为三个岩性段：下部为斜长角肉 片岩、阳起斜长片岩和绿泥斜长片岩段 $\left(\mathrm{Pt}_{2} \mathrm{~b}^{1}\right)$, 中部为长英片岩和变质流纹英安岩段 $\left(\mathrm{Pt}_{2} \mathrm{~b}^{2}\right)$, 以及上部阳起斜长片岩, 变质安山质熔岩和绿泥斜长片岩段 $\left(\mathrm{Pt}_{2} \mathrm{~b}^{3}\right)$. 在白乃庙群东北侧分布 有一东西向延伸, 出露面积约 $30 \mathrm{~km}^{2}$ 的石英闪长岩岩体, 该岩体呈岩株状分别侵位于白银都 西群变质岩系或与白乃庙群断层接触, 部分学者认为石英闪长岩体是加里东期岩浆活动的产 物 ${ }^{[2]}$

表 1 白乃庙群变质基性火山岩和石英闪长岩中锆石铀-铅同位素成分*

\begin{tabular}{|c|c|c|c|c|c|c|c|c|c|c|}
\hline \multirow{2}{*}{ 岩性 } & \multirow{2}{*}{ 吕编号 } & \multicolumn{2}{|c|}{ 含量 (ppm) } & \multicolumn{4}{|c|}{ 同 位 素组 成 } & \multicolumn{3}{|c|}{ 表面年軨 (Ma) } \\
\hline & & U & $\mathrm{Pb}$ & ${ }^{204} \mathrm{~Pb}$ & ${ }^{200} \mathrm{~Pb}$ & ${ }^{207} \mathrm{~Pb}$ & ${ }^{209} \mathrm{~Pb}$ & ${ }^{200} \mathrm{~Pb} / 231$ & ${ }^{200} \mathrm{~Pb} /{ }^{233}$ & $\sqrt{207} \mathrm{~Pb} /{ }^{200} \mathrm{~Pb}$ \\
\hline 残斜 & $2-1$ & 560.69 & 48.40 & 19 & 8282 & 0.054124 & 7 & 14.85 & 557.47 & 783.4 \\
\hline 斑长 & JW2-2 & 198.67 & 14.87 & 0.002037 & 0.828987 & 0.049532 & 0.121481 & 44 & .22 & 592.7 \\
\hline 阳片 & JW2-3 & 793.29 & 61.29 & 0.001112 & 0.827517 & 0.049632 & 0.122850 & 462.2 & 475.61 & 600.13 \\
\hline 起岩 & JW 2-4 & 1033.28 & 62.17 & 0.005598 & 0.826926 & 0.04483 & 0.128041 & 316.3 & 356.75 & 377.3 \\
\hline \multirow{5}{*}{ 石 } & $1-1$ & 0.76 & 8 & 3 & 8 & 0.05 & 2 & & & \\
\hline & JW 1-2 & 432.51 & 36.76 & 0.000829 & 0.834504 & 0.052124 & 0.110373 & 512.6 & 533.78 & 685.4 \\
\hline & JW1-3 & 561.82 & 53.18 & 0.004818 & 0.833537 & 0.054371 & 0.112 & 566.19 & 603.08 & 779.29 \\
\hline & JW1-4 & 208.40 & 11.05 & 0.007191 & 0.829455 & 0.050266 & 0.120279 & 221.09 & 352.78 & 622.37 \\
\hline & JW1-5 & 1161.48 & 97.01 & 0.0005016 & 0.829044 & 0.050257 & 0.129698 & 499.14 & 511.06 & 623.05 \\
\hline
\end{tabular}

*测试单位: 长春地质学院同位美地质年代实验空.

本次研究所用的锆石样品分别采自白乃庙群上部岩性段 $\left(\mathrm{Pt}_{2} \mathrm{~b}^{3}\right)$ 残斑阳起斜长片岩和石 英闪长岩, 其岩矿特征如下:

残斑阳起斜长片岩: 岩石灰绿色, 变余斑状结构, 片状和层状构造. 斑晶主要有斜长石 $(A n-32-39)$, 含量 5-10\% (体积), 角闪石 5-20\%; 基质矿物由钠长石 $(A n-5-10)$ 、 阳起石和绿泥石组成, 副矿物为锆石、桶石、磷灰石和黄铁矿, 岩石地球化学特征与身弧拉斑玄 武岩相似.

1) 内蕞古地质研究队, 内蒙古南部古生代大陆边缘构造特征及其成矿, 1986, 210-216.

2）取风军等，1989 (未刊资料).

第 13 期 
石英闪长岩: 呈灰一灰绿色, 中细粒一不等粒结构,块状或片麻状构造. 矿物含量(体知): 斜长石 $45-65 \%$, 钺长石 1-5\%, 石英 10-20\%, 角闪石和品云泣 3-20\%, 斜长石属中-更 长石 (An - 15-27), 钢长石为隐晶条纹长石 $\left(\mathrm{Or}_{82} \mathrm{Ab}_{13}-\mathrm{Or}_{89} \mathrm{Ab} \mathrm{b}_{12}\right)$, 黑云母为镁铁黑云母, 副 矿物有铅石、磷灰石、磁铁矿和黄铁矿等, 岩矿和地球化学特征均与华南同塎型花岗岩类相类 似 ${ }^{[2]}$.

\section{二、实验结果及讨论}

作者从白乃庙群上部岩性段采得残阳起斜长片岩新鲜岩石样品数百公斤和从石英闪长 岩体采得样品近百公斤, 然后通过粉碎、摇床分选、人工淿洗、电磁选和重液分离等过程, 选取 锆石精矿。锆石颜色、晶形特征和透明度均与典型火山岩中锆石相仿. 锆石溶解、铀、铅提 纯 ${ }^{[3]}$ 和同位素质谱测定均是在长春地质学院同位素实验室完成的, 分析结果见表 1. 锆石铀铅等时线年龄和一致线上、下交点年龄误差均是采用 Ludwig ${ }^{[1]}$ 计算法确定的.

在图 2 中,残阳起斜长片岩四个不同粒级铅石组份点排列在一条直线上, 相关系数 $r=$ 0.9956 , 上交点年龄为 $1130.513 \pm 16.012 \mathrm{Ma}$, 下交点年龄值为 $384.513 \pm 6.062 \mathrm{Ma}$, 从而证明 实验测定精度是可靠的,提高了该年龄数值的可信度.

石英闪长岩中锆石铀-铅同位素测定结果表明: 锆石中放射性成因铅曾发生过不同程度 丢失,因此, 5 个不同粒级锆石组份点铀、铅含量变化范围较大, 在 ${ }^{206} \mathrm{~Pb} /{ }^{238} \mathrm{U}$ 对 ${ }^{207} \mathrm{~Pb} /{ }^{235} \mathrm{U}$ 图 (图 3) 中, 5 个样品点的相关系数 $r=0.9944$, 上交点年龄为 $665.307 \pm 15.293 \mathrm{Ma}$. 很明显, 上述

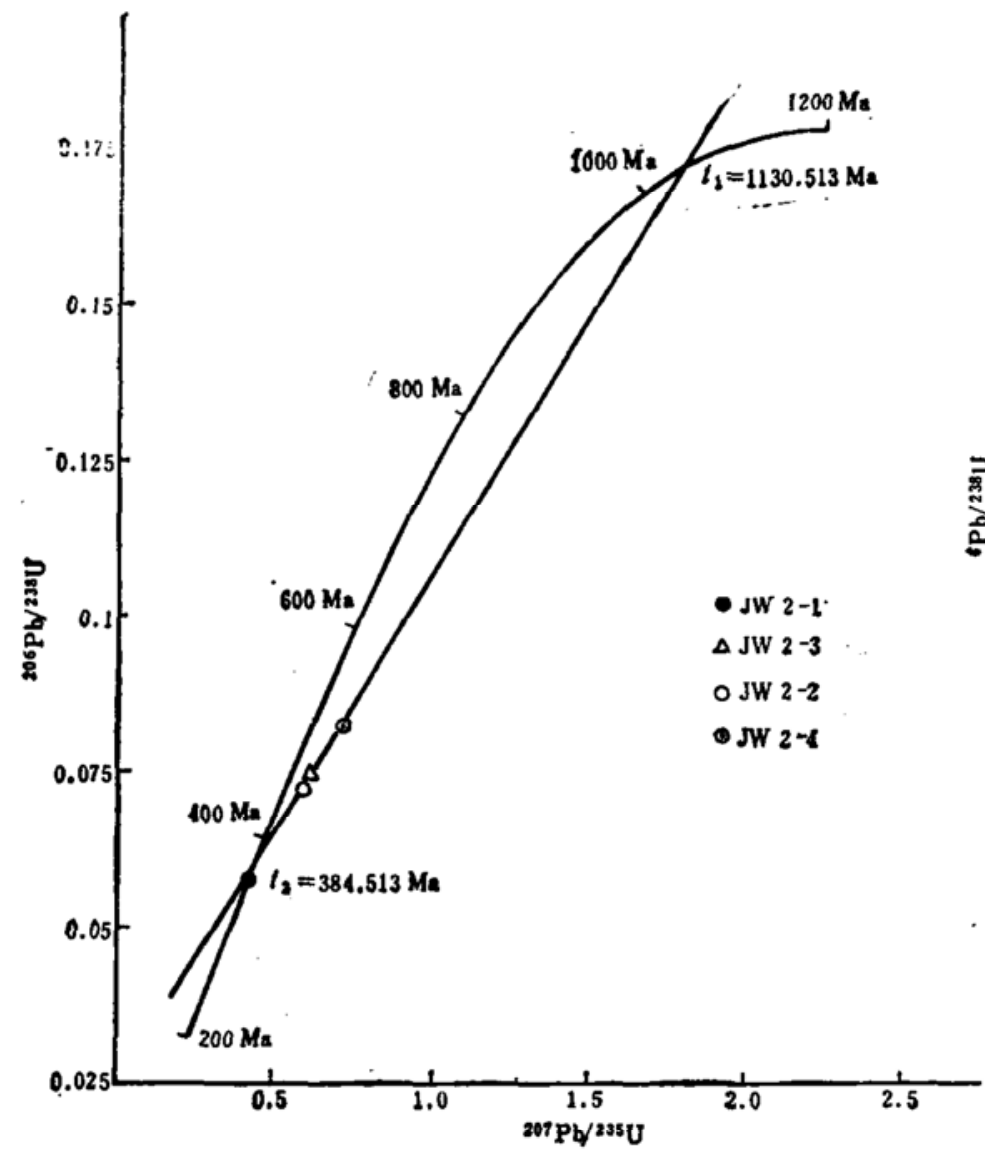

图 2 白乃庙群变质基性火山岩中铅石 (JW2) 铀-铅一致线年龄图

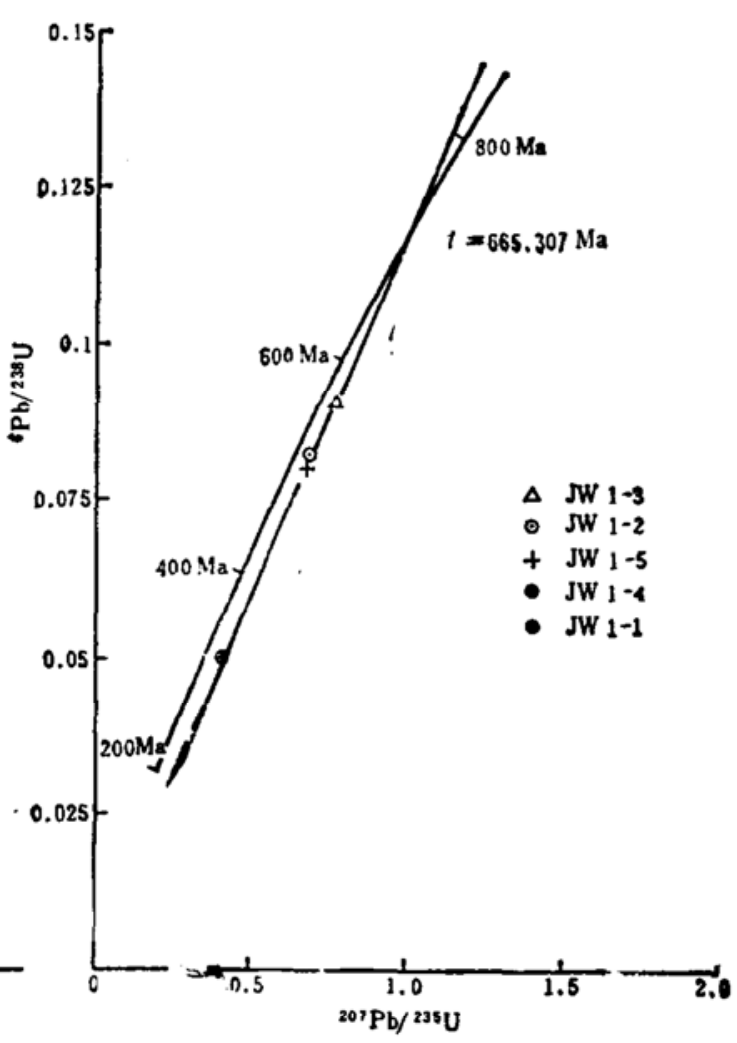

图 3 白乃庙地区石英闪长岩中锆石

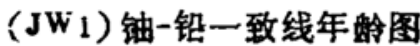


年岭值代表的是锆石铀-铅体系再次封闭后所经历的时间, 据此推测: 石英闪长岩体的上侵定 位时间要早于 $665.307 \pm 15.293 \mathrm{Ma}$.

野外地质调查和锆石铀-铅同位素年龄测定结果表明:

1. 白乃庙群上部岩性段 $\left(\mathrm{Pt}_{2} \mathrm{~b}^{3}\right)$ 中残斑阳起斜长片岩的原岩为典型的海相基性火山熔岩, 其内的锆石为火山环境中形成的单一成因锆石. 锆石的铀一铅年龄代表了白乃庙群上部岩性 段变质基性火山岩的形成时代, 因此, 白乃群形成的上限年龄似为 $1114-1146 \mathrm{Ma}$, 属中元古 代上部.

2. 石英闪长岩成岩时代大于 $665.307 \pm 15.293 \mathrm{Ma}$ ，属新元古代 (New Proterozoic)，而并 非加里东期岩体，锆石中部分放射性成因铅的丢失暗示了岩体形成后曾遭受到强烈区域变质 作用,这种推论与野外地质证据完全吻合.

3. 依据白乃庙群锆石铀一铅年龄数据, 结合北部温都尔庙群幔源花斑岩钾长石铅同位素模 式年龄值 $(1236 \mathrm{Ma} \text { 和 } 776 \mathrm{Ma})^{1)}$, 可以推测: 内蒙古洋板块最早向中朝古陆俯冲的时间应为 中元古代, 而不是早古生代 ${ }^{[3]}$, 因此, 内蒙古中南部温都尔庙一白乃庙沟弧体系形成时代可推前 $580-600 \mathrm{Ma}$.

4. 白乃庙群变质火山喷发沉积岩地层中䟼存有白乃庙大型铜多金属矿床, 其形成过程与 中元古代海底火山活动有关, 所以,在白乃庙草原覆盖区应注意寻找中元古代白乃庙群绿片岩 及其共生的火山岩型铜多金属矿床.

5. 前人所得钾-氯同位素年龄和全岩钢-锶等时线年龄反映了后期区域变质、动力变质和 其它热事件发生的时间,暗示了本区复杂的构造演化历史.

致谢：本文野外工作得到内蒙古地矿局 103 地质队赵贵高级工程师、孙浩、累德武和禁建廷工程师郬 助,室内研究得到林尔为教授协助,暵表表心感谢.

\section{今 文 献}

[1]王东方,中国北方板块构造文集,第 1 集,地质出版社, 1983，209-220.

[2]赵春刜、李之胀,中国北方板块构造文集,第 2 集,地质出版社, 1987, 80-100。

[3] Krongh, T. E., Geochim. Cosmochim. Acsa, 37 (1973), 485-497.

[4] Ludwig. K. R., Earth Planet Sci. Lett., 46(1980), 212.

[5] 祁思辟, 河北地质学院学报, 1979, 3: 1-13.

1) 业凤军等, 中国地质科学院矿床地质研究所所刊, 1990 (待刊稿). 